\title{
Prevalence and management of dementia in primary care practices with electronic medical records: a report from the Canadian Primary Care Sentinel Surveillance Network
}

\author{
Neil Drummond PhD, Richard Birtwhistle MD MSc, Tyler Williamson PhD, Shahriar Khan MSc MA, \\ Stephanie Garies MPH, Frank Molnar MSc MDCM
}

Abstract

Background: The proportion of Canadians living with Alzheimer disease and related dementias is projected to rise, with an increased burden on the primary health care system in particular. Our objective was to describe the prevalence and management of dementia in a community-dwelling sample using electronic medical record (EMR) data from the Canadian Primary Care Sentinel Surveillance Network (CPCSSN), which consists of validated, national, point-of-care data from primary care practices.

Methods: We used CPCSSN data as of Dec. 31, 2012, for patients 65 years and older with at least 1 clinical encounter in the previous 2 years. A validated case definition for dementia was used to calculate the national and provincial prevalence rates, to examine variations in prevalence according to age, sex, body mass index, rural or urban residence, and select comorbid conditions, and to describe patterns in the pharmacologic management of dementia over time at the provincial level.

Results: The age-standardized prevalence of dementia among community-dwelling patients 65 years and older was $7.3 \%$. Prevalence estimates increased with age; they also varied between provinces, and upward trends were observed. Dementia was found to be associated with comorbid diabetes, depression, epilepsy and parkinsonism. Most of the patients with dementia did not have a prescription for a dementia-related medication recorded in their EMR between 2008 and 2012 inclusive. Those who had a prescription were most often prescribed donepezil by their primary care provider.

Interpretation: Overall prevalence estimates for dementia based on EMR data in this sample managed in primary care were generally in line with previous estimates based on administrative data, survey results or clinical sources.

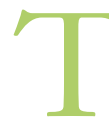
he proportion of Canadians living with Alzheimer disease and related dementias is projected to rise, with an increased burden on the primary health care system in particular. ${ }^{1}$ The Canadian Study of Health and Aging reported a prevalence of dementia of $8 \%$ among community-dwelling individuals and nursing home residents 65 years and older ${ }^{2}$ and remains the standard authority for dementia prevalence in the general Canadian population. ${ }^{3}$ More recently, the Alzheimer Society of Canada estimated the national prevalence of dementia at $14.9 \% .{ }^{4}$ Ontario-based studies using administrative data estimated a prevalence of $7.2 \%$ among community-dwelling people 65 and older., 5 The variability in prevalence estimates is likely due to heterogeneity in the data sources, as well as to differences in case definition.

Community-based primary care settings are typically the first point of contact for people with symptoms of dementia and their caregivers, ${ }^{7}$ and family physicians are vital in achieving effective and efficient diagnosis and management. Improving the assessment and management of dementia in these settings will have a major and growing impact throughout the health and social care system, including modifying demand for specialist services and long-term care placement. Enabling primary care physicians and their associated teams of providers to promote and execute early diagnosis and treatment will likely be a fundamental aspect of emerging pharmaceutical treatments for the disease. It is arguable that the community-based primary

Competing interests: None declared.

This article has been peer reviewed.

Correspondence to: Neil Drummond, neil.drummond@ualberta.ca CMAJ Open 2016. DOI:10.9778/cmajo.20150050 
health care sector has the capacity to respond to the increasing incidence of dementia associated with population aging, ${ }^{8}$ but to do so optimally it must systemically integrate with all relevant health and social care sectors. Understanding the epidemiology and management of dementia among community-dwelling older people in primary care practices is a crucial component in developing such a system.

The Canadian Primary Care Sentinel Surveillance Network (CPCSSN) began in 2008 and represents the equivalent of national primary care surveillance systems such as the Clinical Practice Research Datalink in the United Kingdom. ${ }^{9}$ The CPCSSN extracts, cleans and processes de-identified clinical data every 3 months from the electronic medical records (EMRs) of participating community-based family physicians and primary care nurse practitioners (sentinels). ${ }^{10}$ Sentinels are recruited in a strategic manner to produce a database that is representative of primary care practitioners and patients across Canada. ${ }^{11}$ Sentinels must practise full-service family medicine to be included, although they need not provide obstetric care.

Data from the CPCSSN are contemporaneous and more comprehensive than those available through administrative sources. For instance, physicians are often restricted to submitting a limited number of billing codes for payment, irrespective of how many conditions they were actively managing during a patient encounter. The recording of activities or observations for clinical use rather than for billing purposes creates a wealth of data not available in administrative data sets. Using CPCSSN data for research, surveillance and clinical quality improvement also has advantages over the use of survey data, because EMR data are extracted regularly and inexpensively, provide opportunities for longitudinal follow-up and are based on practitioner report rather than on patient self-report. Most notably, EMR data are directly relevant to primary care clinical practice, organization and policy.

We conducted this study to estimate the prevalence and pharmacologic management of dementia among communitydwelling people 65 years and older attending primary care practices across Canada.

\section{Methods}

\section{Data source and study population}

We used CPCSSN data as of Dec. 31, 2012. At that time, the network included data from 444 sentinel physicians and nurse practitioners providing data on more than 440000 patients from their practices in 7 provinces across Canada. Data from this period have been used consistently in a series of studies describing the prevalence and management of the 8 CPCSSN "index conditions" in primary care, ${ }^{12-16}$ of which this study is the latest.

We included all patients in the CPCSSN database aged 65 years or older on Dec. 31, 2012, who had at least 1 clinic visit recorded in their EMR on or after Jan. 1, 2011. We included information on demographic characteristics, diagnoses, medications, measurements on physical examination (i.e., body mass index [BMI], weight and height) and billing codes.

\section{Case definition for dementia}

We used a case definition for dementia (Box 1) that was developed specifically for use in Canadian primary care EMRs and did not attempt to be applicable in health administrative or other data sets. It included relevant billing codes, diagnostic codes from the patient profile and encounter data, medication data (cholinesterase inhibitors and NMDA [ $N$-methyl-Daspartic acid] medications) and text data. ${ }^{17}$ Validation of the definition produced a sensitivity of $96.8 \%$, specificity of $98.1 \%$, positive predictive value of $72.8 \%$ and negative predictive value of $99.8 \% .{ }^{17}$

\section{Variables of interest}

We examined whether the prevalence of dementia varied by patient characteristics, including age, sex, BMI and rural or urban residence. We chose these characteristics because they are important sociodemographic characteristics in relation to the prevalence and clinical management of chronic disease in primary care. We used BMI values recorded in the EMR; if no value was present, we calculated it using the most recent height and weight values. We classified the BMI values as underweight $(<18)$, normal (18-24), overweight (25-29) and obese $(\geq 30)$. We determined residence in rural or urban areas using the second digit of the patient's postal code (0 indicates rural; other values indicate urban). ${ }^{18}$

We report comorbidity in relation to other chronic conditions for which CPCSSN has a validated case definition (i.e., hypertension, diabetes, chronic obstructive pulmonary disease, osteoarthritis, depression, epilepsy and parkinsonism, including Parkinson disease). ${ }^{17}$

We describe the pharmacologic management of dementia in primary care settings by province, including the type and number of dementia-specific medications (donepezil, galantamine, memantine and rivastigmine) prescribed by a primary care practitioner. We considered a dementia-specific drug to have been used if there was at least 1 prescription for that medication recorded in the EMR. We were unable to confirm whether patients had been prescribed medications elsewhere (e.g., from a specialist) or whether the prescription was filled or taken as directed.

For province-specific subanalyses, we calculated age- and sex-adjusted prevalence rates from 2008 to 2012 for dementia in Alberta, Manitoba, Ontario, Nova Scotia, and Newfoundland and Labrador. We excluded British Columbia and Quebec from these analyses because their samples of patients and providers were small and may not reflect broader provincial trends. At the time of our study, CPCSSN did not have dataextraction processes in Saskatchewan, New Brunswick, Prince Edward Island or the Territories.

\section{Statistical analysis}

We used a combination of descriptive statistics and multivariate modelling using SAS software, version 9.3. Two separate log-binomial regression analyses were carried out to calculate prevalence, each controlling for age and sex of the study population according to national population distributions, ${ }^{19}$ and to explore associations with residence location and BMI cate- 
gory. In addition, we analyzed the presence of comorbid conditions using the same log-binomial approach, adjusting for age and sex. Results are expressed as prevalence ratios with $95 \%$ confidence intervals (CIs).

\section{Results}

Of the 59177 community-dwelling patients aged 65 years and older for whom we extracted data, 4552 were identified as having dementia, for a crude prevalence estimate of $7.7 \%$. Prevalence estimates for dementia rose with increasing age, with women aged 85 or older showing a slightly higher prevalence than men in the same age group $(22.5 \%$ v. $20.5 \%)$
(Table 1). After adjusting for age and sex, we found a significant decrease in the prevalence of dementia among patients who were obese compared with those of normal weight (prevalence ratio $0.89,95 \%$ CI $0.81-0.97$ ) and a significant increase in prevalence associated with comorbid diabetes, depression, epilepsy and parkinsonism (Table 2). The prevalence of dementia was lower among patients living in rural settings than among those in urban locations, although the difference was not significant (Table 2).

Table 3 provides an overview of the pharmacologic management of dementia in primary care by province from 2008 to 2012. Most of the patients with dementia did not receive a prescription for a dementia-related medication from their pri-

\section{Box 1: Case definition for dementia* developed by the Canadian Primary Care Sentinel Surveillance Network}

Classification can occur by meeting criteria in any of the sections below (billing, problem list/encounter diagnosis, medication), unless specified otherwise

Billing Problem list/encounter diagnosis

Any occurrence of the following

ICD-9 codes:

- 290.* - dementias psychosis

- 331. * other cerebral degenerations

- 294.1 - dementia in conditions classified elsewhere

- 294.8 - other persistent mental disorders due to conditions classified elsewhere

- $797 .^{*}$ - senility without mention of psychosis

- 438. ${ }^{*}$ - late effects of cerebrovascular disease psychosis

The following are excluded:

- 290.8 - other specified senile psychotic condition

- 331.3 - communicating hydrocephalus

- 331.4 - obstructive hydrocephalus

- 331.5 - idiopathic normal pressure hydrocephalus

- 331.81 - Reye syndrome
Any occurrence of the following

ICD-9 codes:

- 290.* - dementias psychosis

- 331. * - other cerebral degenerations

- 294.1 - dementia in conditions classified elsewhere

- 294.8 - other persistent mental disorders due to conditions classified elsewhere

- 797.* - senility without mention of psychosis

- 438. ${ }^{*}$ - late effects of cerebrovascular disease psychosis

The following are excluded:

- 290.8 - other specified senile psychotic condition

- 331.3 - communicating hydrocephalus

- 331.4 - obstructive hydrocephalus

- 331.5 - idiopathic normal pressure hydrocephalus

- 331.81 - Reye syndrome

Note: ATC = Anatomical Therapeutic Chemical Classification System, ICD-9 = International Classification of Diseases, 9th revision.

*Includes Alzheimer disease, frontotemporal dementia, Pick disease, senile degeneration of the brain, corticobasal degeneration, cerebral degeneration, dementia with Lewy bodies, mild cognitive impairment, senile dementia, presenile dementia, vascular dementia, senility without mention of psychosis.

Table 1: Prevalence of dementia, by age and sex

Sex; \% of patients $(n / N)[95 \% \mathrm{Cl}]$

\begin{tabular}{|c|c|c|}
\hline \multirow[b]{2}{*}{ Age group, yr } & \multirow{2}{*}{ Male } & \multirow{2}{*}{ Female } \\
\hline & & \\
\hline $65-74$ & $2.4(336 / 13$ 964) [2.2-2.7] & $2.5(426 / 16$ 914) [2.3-2.8] \\
\hline $75-84$ & $9.0(745 / 8$ 243) [8.4-9.7] & 9.7 (1 067/10 978) [9.2-10.3] \\
\hline$\geq 85$ & $20.5(648 / 3$ 158) [8.4-9.7] & 22.5 (1 330/5 920) [21.4-23.5] \\
\hline Total (observed) & \multicolumn{2}{|c|}{7.7 (4 552/59 177) [7.5-7.9] } \\
\hline Total (age and sex standardized) & \multicolumn{2}{|c|}{$7.3[7.1-7.5]$} \\
\hline
\end{tabular}


mary care provider, although the proportion decreased over time. Among patients who were prescribed a medication for dementia, most had received a prescription for 1 drug only, and the majority of prescriptions were for donepezil in all provinces except for Nova Scotia, where galantamine was more frequently prescribed in 2009 and 2010.

Age- and sex-adjusted prevalence estimates at the provincial level, to explore variations across Canada and over time, are shown in Figure 1 and in Appendix 1 (available at www. cmajopen.ca/content/4/2/E177/supp1/DC1). Alberta, Manitoba, Nova Scotia and Ontario had considerable increases in the prevalence of dementia from 2008 to 2012. In 2012, the dementia prevalence was highest in Ontario (7.4\%) and lowest in Newfoundland and Labrador (5.7\%).

\section{Interpretation}

Our estimate of the age-standardized prevalence of dementia among community-dwelling people 65 years and older was $7.3 \%$. Global estimates of dementia in primary care settings have ranged from $5 \%$ to $10 \% .{ }^{20-22}$ Our finding may be an underestimate, because many physician-specific and systemwide factors preclude swift diagnosis in primary care. It is inevitable that nondiagnosis of some incident cases will occur, especially for a condition such as dementia, whose onset is insidious, even in a sample which, by definition, is known to

Table 2: Factors influencing the prevalence of dementia, adjusted for age and sex

\begin{tabular}{|lcc|}
\hline Factor & No. of patients & $\begin{array}{c}\text { Prevalence ratio } \\
(95 \% \mathrm{Cl})\end{array}$ \\
\hline Residence location & & \\
\hline Urban & 42940 & $1.00($ ref $)$ \\
\hline Rural & 14438 & $0.93(0.87-1.00)$ \\
\hline Missing data & 1799 & $1.50(1.36-1.67)$ \\
\hline Weight category (BMI) & & \\
\hline Normal (18-24) & 12246 & $1.00($ ref $)$ \\
\hline Underweight $(<18)$ & 1552 & $1.13(0.98-1.33)$ \\
\hline Overweight $(25-29)$ & 14510 & $0.94(0.87-1.03)$ \\
\hline Obese $(\geq 30)$ & 12843 & $0.89(0.81-0.97)$ \\
\hline Missing data & 18026 & $1.03(0.96-1.11)$ \\
\hline Comorbidity & & \\
\hline Hypertension & 30691 & $0.97(0.95-1.00)$ \\
\hline Diabetes & 13130 & $1.10(1.04-1.16)$ \\
\hline Depression & 9355 & $2.40(2.29-2.52)$ \\
\hline COPD & 6704 & $1.08(1.00-1.17)$ \\
\hline Osteoarthritis & 17028 & $1.01(0.97-1.06)$ \\
\hline Epilepsy & 592 & $2.89(2.32-3.60)$ \\
\hline Parkinsonism & 794 & $2.93(2.47-3.47)$ \\
\hline $\begin{array}{l}\text { Note: BMI = body mass index, Cl = confidence interval, COPD = chronic } \\
\text { obstructive pulmonary disorder, ref }=\text { reference group. }\end{array}$ & \\
\hline & & \\
\hline
\end{tabular}

have seen a physician in the last 2 years. Although the majority of patients experiencing the first signs of dementia initially visit a primary care provider, many, if not most, appear to have their diagnosis confirmed by a specialist. ${ }^{23}$ This suggests that primary care practitioners need training and experience to undertake routine diagnosis and management without referral. Reasons for dementia diagnoses occurring in specialist practices rather than primary care are multifaceted and include primary care providers having a lack of confidence in dementia knowledge and support resources; concern about misdiagnosis; perception of usefulness of diagnosis and treatment options; and lack or mistrust of screening tools. ${ }^{20,22,23}$ In recent years, new models for dementia care have become widespread in primary care practices, ${ }^{24}$ which may facilitate the management of these patients in that setting.

The discrepancies between diagnosis in primary and specialist care may also explain why most of the patients with dementia in our study did not have a prescription for a dementia-specific medication in their EMR. Although the family physician is typically the first point of contact for communitybased patients with dementia, prescription of medication is often split between them and specialists. ${ }^{25,26}$ Patterns of prescription among primary care physicians are markedly similar across several countries, despite differences in health and insurance systems. The most frequently prescribed medications are cholinesterase inhibitors (e.g., galantamine, donepezil and rivastigmine) and NMDA antagonists (e.g., memantine), reported in $50 \%-90 \%$ of cases. ${ }^{27-29}$ Our estimate for the proportion of patients prescribed these medications by their primary care provider was lower than that reported elsewhere and may reflect legitimate uncertainty in Canada about their effectiveness. ${ }^{30,31}$ It may also reflect incomplete recording of prescribing by specialists in primary care EMRs. Provincial prescribing policies related to these medications are also likely additional sources of variance.

Our prevalence estimates for dementia in primary care practices by province over time indicate expected rates of increase in most provinces associated with the aging population, with Ontario showing the highest prevalence in 2012 (7.4\%). Newfoundland and Labrador was an exception, having the lowest prevalence in 2012 and not showing a steady increase since 2008. The reasons for this require further investigation. It could be that dementia patients in Newfoundland and Labrador may be entering long-term care facilities more readily than their counterparts in other provinces. It may be that dementia is not being diagnosed in primary care as readily as it is in patients elsewhere. These findings highlight the importance of appropriate health services planning, because most provinces identified in our study have seen rates of dementia in primary care rise by $30 \%-50 \%$ from 2008 to 2012 .

Across the country, we observed a lower prevalence of dementia among patients living in rural areas than among those in urban settings. Although this difference was not significant, it may suggest that patients with dementia are likely to move to urban locations where they can access services related to their condition or to reside closer to family living in town. 


\begin{tabular}{|c|c|c|c|c|c|}
\hline \multirow[b]{2}{*}{ Variable } & \multicolumn{5}{|c|}{ Year; no. (\%) of patients } \\
\hline & 2008 & 2009 & 2010 & 2011 & 2012 \\
\hline \multicolumn{6}{|l|}{ Alberta } \\
\hline \multicolumn{6}{|c|}{ No. of medications* } \\
\hline 0 & $658(94.8)$ & $632(91.1)$ & $616(88.6)$ & $616(88.8)$ & $609(87.8)$ \\
\hline 1 & $33(4.8)$ & $60(8.7)$ & $77(11.1)$ & $75(10.8)$ & 85 (12.3) \\
\hline 2 & $3(0.4)$ & $2(0.3)$ & $1(0.1)$ & $3(0.4)$ & 0 \\
\hline $3-4$ & 0 & 0 & $1(0.1)$ & 0 & 0 \\
\hline \multicolumn{6}{|c|}{ Type of medication $†$} \\
\hline Donepezil & $21(60.0)$ & $21(65.6)$ & $28(62.2)$ & $29(72.5)$ & $57(67.1)$ \\
\hline Galantamine & $13(37.1)$ & 7 (21.9) & $17(37.8)$ & $12(30.0)$ & $24(28.2)$ \\
\hline Memantine & $4(11.4)$ & $2(6.3)$ & $1(2.2)$ & $1(2.5)$ & 7 (8.2) \\
\hline Rivastigmine & $4(11.4)$ & $4(12.5)$ & $3(6.7)$ & $7(17.5)$ & $9(10.6)$ \\
\hline \multicolumn{6}{|l|}{ Manitoba } \\
\hline \multicolumn{6}{|c|}{ No. of medications* } \\
\hline 0 & $466(94.1)$ & $456(92.1)$ & $446(90.1)$ & $445(89.9)$ & $445(89.0)$ \\
\hline 1 & $28(5.7)$ & $38(7.7)$ & $48(9.7)$ & $49(9.9)$ & $49(9.9)$ \\
\hline 2 & $1(0.2)$ & $1(0.2)$ & $1(0.2)$ & $1(0.2)$ & $1(0.2)$ \\
\hline $3-4$ & 0 & 0 & 0 & $1(0.2)$ & 0 \\
\hline \multicolumn{6}{|c|}{ Type of medication $†$} \\
\hline Donepezil & $11(91.7)$ & $11(84.6)$ & $14(82.4)$ & $17(77.3)$ & $47(94.0)$ \\
\hline Galantamine & $1(8.3)$ & $4(30.8)$ & $2(11.8)$ & $7(31.8)$ & $4(8.0)$ \\
\hline Memantine & 0 & 0 & 0 & 0 & $1(2.0)$ \\
\hline Rivastigmine & $1(8.3)$ & 0 & $1(5.9)$ & $1(4.6)$ & $3(6.0)$ \\
\hline \multicolumn{6}{|l|}{$\begin{array}{l}\text { Newfoundland } \\
\text { and Labrador }\end{array}$} \\
\hline \multicolumn{6}{|c|}{ No. of medications* } \\
\hline 0 & $271(92.8)$ & $253(86.6)$ & $227(77.7)$ & 207 (70.9) & $207(70.9)$ \\
\hline 1 & $20(6.9)$ & $34(11.6)$ & $62(21.2)$ & $83(28.4)$ & $83(28.4)$ \\
\hline 2 & 0 & $4(1.4)$ & $3(1.0)$ & $1(0.3)$ & $2(0.7)$ \\
\hline $3-4$ & $1(0.3)$ & $1(0.3)$ & 0 & $1(0.3)$ & 0 \\
\hline \multicolumn{6}{|c|}{ Type of medication $†$} \\
\hline Donepezil & $6(66.7)$ & $7(77.8)$ & $16(64.0)$ & $29(65.9)$ & 75 (88.2) \\
\hline Galantamine & 3 (33.3) & $2(22.2)$ & $9(36.0)$ & $22(50.0)$ & $16(18.8)$ \\
\hline Memantine & $1(11.1)$ & $1(11.1)$ & $5(20.0)$ & $1(2.3)$ & 0 \\
\hline Rivastigmine & $2(22.2)$ & 0 & $1(4.0)$ & $2(4.6)$ & $1(1.2)$ \\
\hline \multicolumn{6}{|c|}{ Nova Scotia } \\
\hline \multicolumn{6}{|c|}{ No. of medications* } \\
\hline 0 & $491(89.9)$ & $468(85.7)$ & $429(78.6)$ & $383(70.2)$ & $397(72.7)$ \\
\hline 1 & $51(9.3)$ & $73(13.4)$ & $110(20.2)$ & $154(28.2)$ & $139(25.5)$ \\
\hline 2 & $4(0.7)$ & $5(0.9)$ & $7(1.3)$ & $8(1.5)$ & $10(1.8)$ \\
\hline $3-4$ & 0 & 0 & 0 & $1(0.2)$ & 0 \\
\hline \multicolumn{6}{|c|}{ Type of medication $†$} \\
\hline Donepezil & $7(53.9)$ & $2(18.2)$ & $14(53.9)$ & $38(56.7)$ & $90(60.4)$ \\
\hline Galantamine & $4(30.8)$ & $9(81.8)$ & $16(61.5)$ & $29(43.3)$ & $62(41.6)$ \\
\hline Memantine & $1(7.7)$ & 0 & $1(3.9)$ & $3(4.5)$ & $8(5.4)$ \\
\hline Rivastigmine & $1(7.7)$ & 0 & $2(7.7)$ & $7(10.5)$ & $17(11.4)$ \\
\hline
\end{tabular}




\section{OPEN}

Research

\begin{tabular}{|c|c|c|c|c|c|}
\hline \multirow[b]{2}{*}{ Variable } & \multicolumn{5}{|c|}{ Year; no. (\%) of patients } \\
\hline & 2008 & 2009 & 2010 & 2011 & 2012 \\
\hline \multicolumn{6}{|l|}{ Ontario } \\
\hline \multicolumn{6}{|c|}{ No. of medications* } \\
\hline 0 & $1934(92.8)$ & $1812(86.9)$ & $1678(80.5)$ & $1589(76.2)$ & $1557(74.7)$ \\
\hline 1 & $135(6.5)$ & $248(11.9)$ & $357(17.1)$ & $432(20.7)$ & $459(22.0)$ \\
\hline 2 & $14(0.7)$ & $23(1.1)$ & $49(2.4)$ & $62(3.0)$ & $66(3.2)$ \\
\hline $3-4$ & $2(0.1)$ & $2(0.1)$ & $1(0.1)$ & $2(0.1)$ & $3(0.1)$ \\
\hline \multicolumn{6}{|c|}{ Type of medication† } \\
\hline Donepezil & $25(67.6)$ & $30(63.8)$ & $68(58.6)$ & $138(60.3)$ & $343(62.9)$ \\
\hline Galantamine & $8(21.6)$ & $18(38.3)$ & $49(42.2)$ & $81(35.4)$ & $191(35.1)$ \\
\hline Memantine & $4(10.8)$ & $5(10.6)$ & 15 (12.9) & $45(19.7)$ & 95 (17.4) \\
\hline Rivastigmine & $3(8.1)$ & 7 (14.9) & $12(10.3)$ & $27(11.8)$ & $59(10.8)$ \\
\hline
\end{tabular}

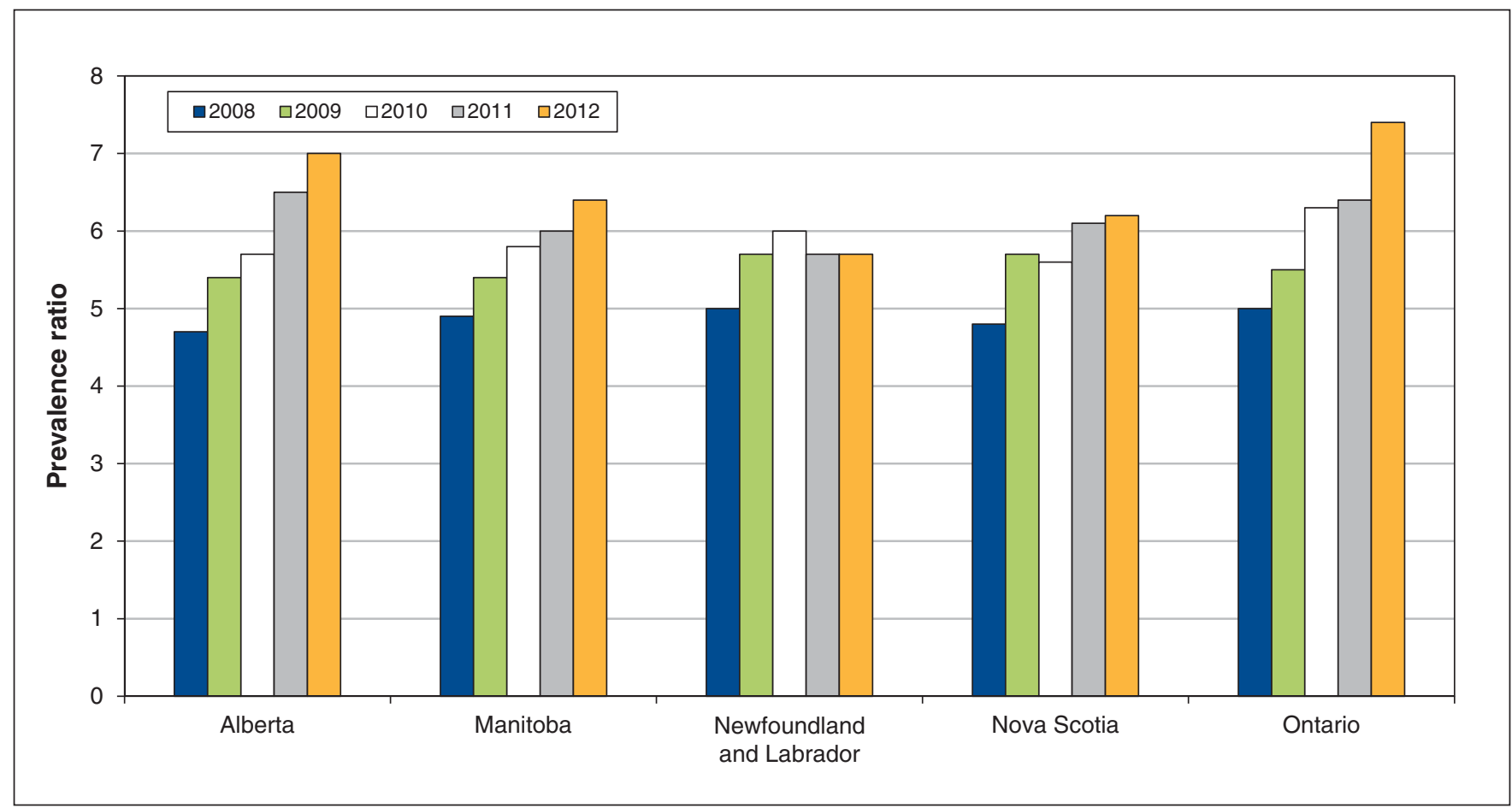

Figure 1: Age- and sex-standardized prevalance of dementia among community-dwelling patients aged 65 years and older, by year and province (for supporting data, see Appendix 1, available at www.cmajopen.ca/content/4/2/E177/suppl/DC1).

Although obesity is considered to be moderately associated with dementia, ${ }^{32}$ we found a significant decrease in the prevalence of dementia among obese patients. This may reflect lower food consumption among people with dementia. ${ }^{33}$

Comorbid conditions that we found to be associated with a higher prevalence of dementia included diabetes, depression, epilepsy and parkinsonism. In this, our data both supports and diverges from previous research. The most frequent comorbid conditions previously reported in dementia patients include coronary artery disease, diabetes, congestive heart failure and hypertension. ${ }^{34,35}$ A US study found that $95 \%$ of patients with dementia had 1 or more comorbid conditions, with $26 \%$ having coronary artery disease and $23 \%$ having diabetes. ${ }^{36}$ In a Canadian study, $19.5 \%$ of dementia patients had a mood dis- 
order compared with $5.3 \%$ in a group of the same age without dementia. ${ }^{37} \mathrm{We}$ found no association between dementia and hypertension in our study population despite the current recognition of cardiovascular disease as a risk factor for dementia. Further development of the case definition for dementia will be needed to analyze the association with other important comorbid conditions, such as coronary artery disease and congestive heart failure, for which CPCSSN does not currently have validated case definitions.

\section{Limitations}

The CPCSSN database contains only data entered into primary care EMRs. Also, the data are only for patients who attend participating primary care practices. Although this generally excludes residents in long-term care facilities, most Canadians living in the community visit their family physician at least once each year, ${ }^{38}$ and we took strategic sampling measures to ensure representativeness of the data at a national level. ${ }^{11}$

The quality of dementia diagnoses in primary care is considered to be variable, with some family physicians confident to diagnose without referral or imaging and others making use of those supports to varying degrees. ${ }^{39}$ Efforts to improve the diagnosis and management of dementia in primary care include the implementation of primary care-based memory clinics, ${ }^{24}$ which attempt to capitalize on the particular expertise of family physicians with specific interest in the disease. Differentiating between different types of dementia is not currently possible within the CPCSSN database for reasons associated with data-recording behaviour among physicians, nor does CPCSSN data include information on other important aspects of community-based care, such as counselling, home care and advanced care planning.

Data quality can often be an issue with large primary care EMR databases, because these data are input for clinical purposes and not with research applications in mind. For instance, $30.5 \%$ of patients with the diagnosis of dementia in the CPCSSN database were missing BMI values and 3\% did not have a postal code to confirm their urban or rural residence status. This may have caused our association between obesity and lower rates of dementia to be invalid, if the BMI data were missing in a nonrandom pattern. Data on smoking status are inconsistently recorded in primary care EMRs, both in form and content, and thus were excluded from our study. A misclassification bias may also exist, because the EMR database may not capture all community-dwelling patients with dementia, and our prevalence may thus be underestimated; however, our validity estimates for identifying cases of dementia in primary care EMRs are robust. ${ }^{17}$

\section{Conclusion}

The existence of robust health and utilization data in primary care is crucial for primary care development in Canada. Our analysis of dementia among community-dwelling patients aged 65 years and older based on EMR data from primary care settings across the country provides important insight into longitudinal prevalence estimates and aspects of pharmacologic management at a time when the prevalence of dementia and the demand for support are increasing. Understanding and improving the provision of primary care services for dementia is essential to maintain standards of care and the health of the nation. Achieving this includes an urgent need for improved undergraduate medical training and continuing medical education in the diagnosis and management of dementia, and the development and evaluation of EMR-based care pathways and other innovations for the support of patients and caregivers as well as community-based primary care providers.

\section{References}

1. Mapping connections: an understanding of neurological conditions in Canada. Ottawa: Public Health Agency of Canada; 2014.

2. Canadian Study of Health and Aging Working Group. Canadian Study of Health and Aging: study methods and prevalence of dementia. CMA7 1994;150:899-913.

3. Graham JE, Rockwood K, Beattie BL, et al. Prevalence and severity of cognitive impairment with and without dementia in an elderly population. Lancet 1997;349:1793-6.

4. A new way of looking at the impact of dementia in Canada. Toronto: Alzheimer Society of Canada; 2012.

5. Ng R, Maxwell CJ, Yates EA, et al. Brain disorders in Ontario: prevalence, incidence and costs from bealth administrative data. Toronto: Institute for Clinical Evaluative Sciences; 2015.

6. Gill SS, Camacho X, Poss JW. Community-dwelling older adults with dementia. In: Bronskill SE, Camacho X, Gruneir A, et al., editors. Health system use by frail Ontario seniors: an in-depth examination of four vulnerable coborts. Toronto: Institute for Clinical Evaluative Sciences; 2011.

7. Hum S, Cohen C, Persaud M, et al. Role expectations in dementia care among family physicians and specialists. Can Geriatr 7 2014;17:95-102.

8. Rising tide: the impact of dementia on Canadian society. Toronto: Alzheimer Society of Canada; 2010.

9. Herrett E, Gallagher AM, Bhaskaran K, et al. Data resource profile: Clinical Practice Research Datalink (CPRD). Int 7 Epidemiol 2015;44:827-36.

10. Birtwhistle RV. Canadian Primary Care Sentinel Surveillance Network: a developing resource for family medicine and public health. Can Fam Physician 2011;57:1219-20.

11. Queenan J, Williamson T, Khan S, et al. Representativeness of patients and providers in the Canadian Primary Care Sentinel Surveillance Network: a cross-sectional study. CMA7 Open 2016;4:E28-32.

12. Birtwhistle R, Morkem R, Peat G, et al. Prevalence and management of osteoarthritis in primary care: an epidemiologic cohort study from the Canadian Primary Care Sentinel Surveillance Network. CMA7 Open 2015;3:E270-5.

13. Green ME, Natajaran N, O'Donnell DE, et al. Chronic obstructive pulmonary disease in primary care: an epidemiologic cohort study from the Canadian Primary Care Sentinel Surveillance Network. CMA7 Open 2015;3:E15-22.

14. Godwin M, Williamson T, Khan S, et al. Prevalence and management of hypertension in primary care practices with electronic medical records: a report from the Canadian Primary Care Sentinel Surveillance Network. CMAJ Open 2015;3:E76-82.

15. Wong ST, Manca D, Barber D, et al. The diagnosis of depression and its treatment in Canadian primary care practices: an epidemiological study. CMAJ Open 2014;2:E337-42.

16. Greiver M, Williamson T, Barber D, et al. Prevalence and epidemiology of diabetes in Canadian primary care practices: a report from the Canadian Primary Care Sentinel Surveillance Network. Can 7 Diabetes 2014;38:179-85.

17. Williamson T, Green ME, Birtwhistle R, et al. Validating the 8 CPCSSN case definitions for chronic disease surveillance in a primary care database of electronic health records. Ann Fam Med 2014;12:367-72.

18. Addressing guidelines. Ottawa: Canada Post Corporation; 2014. Available: www.canadapost.ca/tools/pg/manual/PGaddress-e.asp\#1383055 (accessed 2015 Jan. 28).

19. 2011 census of population. Ottawa: Statistics Canada; 2012. Cat no 98-311-XCB2011018.

20. Connolly A, Gaehl E, Martin H, et al. Underdiagnosis of dementia in primary care: variations in the observed prevalence and comparisons to the expected prevalence. Aging Ment Health 2011;15:978-84.

21. Cruz-Orduña I, Bellón JM, Torrero P, et al. Detecting MCI and dementia in primary care: efficiency of the MMS, the FAQ and the IQCODE. Fam Pract 2012;29:401-6.

22. Bradford A, Kunik ME, Schulz P, et al. Missed and delayed diagnosis of dementia in primary care: prevalence and contributing factors. Alzheimer Dis Assoc Disord 2009;23:306-14.

23. Aminzadeh F, Molnar FJ, Dalziel WB, et al. A review of barriers and enablers to diagnosis and management of persons with dementia in primary care. Can Geriatr 7 2012;15:85-94.

24. Lee L, Hillier LM, Heckman G, et al. Primary care-based memory clinics: expanding capacity for dementia care. Can f Aging 2014;33:307-19. 
25. Hillmer M, Krahn M, Hillmer M, et al. Prescribing patterns for Alzheimer disease: survey of Canadian family physicians. Can Fam Physician 2006;52:208-9.

26. Jeschke E, Ostermann T, Vollmar HC, et al. Prescribing patterns in dementia: a multicentre observational study in a German network of CAM physicians. BMC Neurol 2011;11:99-109.

27. Fortinsky RH, Zlateva I, Delaney C, et al. Primary care physicians' dementia care practices: evidence of geographic variation. Gerontologist 2010;50:179-91.

28. Jedenius E, Johnell K, Fastbom J, et al. Dementia management programme in a community setting and the use of psychotropic drugs in the elderly population. Scand 7 Prim Health Care 2011;29:181-6.

29. Rattinger GB, Burcu M, Dutcher SK, et al. Pharmacotherapeutic management of dementia across settings of care. 7 Am Geriatr Soc 2013;61:723-33.

30. Molnar FJ, Man-Son-Hing M, Hutton B, et al. Have last-observation-carriedforward analyses caused us to favour more toxic dementia therapies over less toxic alternatives? A systematic review. Open Med 2009;3:e31-50.

31. Bond M, Rogers G, Peters J, et al. The effectiveness and cost-effectiveness of donepezil, galantamine, rivastigmine and memantine for the treatment of Alzheimer's disease (review of Technology Appraisal no. 111): a systematic review and economic model. Health Technol Assess 2012;16:1-470.

32. Beydoun MA, Beydoun HA, Wang Y. Obesity and central obesity as risk factors for incident dementia and its subtypes: a systematic review and meta-analysis. Obes Rev 2008;9:204-18.

33. Jackson J, Currie K, Graham C, et al. The effectiveness of interventions to reduce undernutrition and promote eating in older adults with dementia: a systematic review. 7BI Library Syst Rev 2011;9:1509-50.

34. Prince M, Acosta D, Ferri CP, et al. The association between common physical impairments and dementia in low and middle income countries, and among people with dementia, their association with cognitive function and disability. A 10/66 Dementia Research Group population-based study. Int 7 Geriatr Psychiatry 2011;26:511-9.

35. Kurrle S, Brodaty H, Hogarth R. Physical comorbidities of dementia. Cambridge (UK): University Press; 2012.

36. Lazaroff A, Morishita L, Schoephoerster G, et al. Using dementia as the organizing principle when caring for patients with dementia and comorbidities. Minn Med 2013;96:41-6.
37. Nabalamba A, Patten SB. Prevalence of mental disorders in a Canadian household population with dementia. Can 7 Neurol Sci 2010;37:186-94.

38. Nabalamba A, Millar WJ. Going to the doctor. Health Rep 2007;18:23-35.

39. Pimlott NJG, Persaud M, Drummond N, et al. Family physicians and dementia in Canada. Part 2. Understanding the challenges of dementia care. Can Fam Physician 2009;55:508-9.e1-7.

Affiliations: Department of Family Medicine (Drummond), University of Alberta, Edmonton, Alta.; Family Medicine and Public Health Services (Birtwhistle), Queen's University, Kingston, Ont.; Department of Community Health Sciences (Williamson), Cumming School of Medicine, University of Calgary, Calgary, Alta.; Department of Family Medicine (Khan), Queen's University, Kingston, Ont.; Departments of Family Medicine and Community Health Sciences (Garies), University of Calgary, Calgary, Alta.; Division of Geriatric Medicine (Molnar), University of Ottawa and The Ottawa Hospital, Ottawa Hospital Research Institute, Bruyere Research Institute, Ottawa, Ont.

Contributors: All the authors contributed to the conceptualization, planning and design of the study, the interpretation of data and the writing of the manuscript. Data analysis was undertaken mainly by Shahriar Khan, with guidance from Tyler Williamson and the assistance of Rick Birtwhistle, Stephanie Garies and Neil Drummond. All of the authors approved the final version to be published and agreed to act as guarantors of the work.

Funding: This work was supported by the Public Health Agency of Canada's Canadian Chronic Disease Surveillance System - Neurological Diseases Working Group (project no. 6271-15-2010/3970783).

Supplemental information: For reviewer comments and the original submission of this manuscript, please see www.cmajopen.ca/content/4/2/ E177/suppl/DC1 